\title{
Medical Instructions of the XVIII Century to Resuscitate the Apparently Dead: Rescuing the Drowned to Define the Origins of the Emergency Medicine
}

\author{
Silvia Marinozzi, Giuliano Bertazzoni and Valentina Gazzaniga \\ "Sapienza" University of Rome \\ Italy
}

\section{Introduction}

The concept of an emergency therapeutic action, defined as an immediate intervention to save dying people, is absent from the ancient medical mind. The Hippocratic physician cures diseases, defined as states of functional alterations of the natural processes: the pathologies are considered to be manifestations of a dyscrasia, or rather an imbalance of the body's components, by excess or by default of quality and moods, which moves the physis of the body away from its natural condition. The altered organic processes are explained as a consequence of an inappropriate life style, that is a wrong regime which alters and compromises the functions of the entire organism: the quantity and quality of food and pothos, the relation between waking and sleeping, the hygienic and living conditions, the physical change, sexual activity, in an holistic conception which does not involve a medical intervention in contrast with the process in act. The diseases must follow their course, grow and reach the Krisis, the moment of a definite change, which brings towards death or healing. The physician acts in order to re-establish the original equilibrium of the body, though respecting the natural course of the phenomena and thus avoiding to intervene on those who cannot be saved.

The observation of the signs helps in prognosticating healing or death, thus determining the conduct of the physician who cures and gives therapeutic indications only for those diseases and ailments which are deemed curable. The duration of the medical intervention therefore follows that of pathologic course, without any forced action which would interrupt the natural evolution of the process in course.

Prognosis, or rather the prediction of an illness in course in order to decide whether healing is possible or not, is the highest expression of the clinical reasoning of ancient medicine. It will only be the development of human anatomy as a scientific medical discipline, in the XVI Century, to pave the way to conceive new therapeutic measures and above all to boost surgery, which enables a different approach to the cure so as to contrast the process of death in course, and intervenes promptly in the medications of injuries and wounds, developing new systems of hemorrhagic arrest. But the concept of first aid, that is an immediate medical intervention aimed at saving dying people, finds its specific theoretic connotation only in 
the XVIII Century, when research and the applications of systems of defense and protection of human life becomes a concrete expression of social medicine and public health policies in the Enlightenment. A specific medical literature of health education is developed in the genres of "instructions" or textbooks addressed to the general public, to inform about the disease's risks the people might be exposed to, to educate on prevention and prophylaxis, and to teach techniques for immediate relief and for the care of victims of frequent accidents. The aim the contribution is to present the most recurrent topics in this medical literature as the first step for the formation of a theoretical basis of emergency medicine, which is reflected in the resuscitation of asphyxiated resuscitation techniques developed by medical authors.

\section{Rescuing the drowned: the resuscitation of the apparently dead}

The concept of reanimation defined as a group of medical actions coordinated in order to reestablish the basic vital functions of a single being, is historically connected to the matter of sudden deaths and above all of apparent death.

It is in fact the fear of burying live people that represents the crucial point towards the development of a medical doctrine on the causes of sudden deaths and above all on the procedures carried out to assess legal death through a codification of the signs relevant to real death. Following this theory the first guidelines have been developed in order to elaborate systems of reanimation of apparent dead people: the same techniques are used to assess legal death can reactivate those organic functions which expired without actually causing the real death of a person.

In 1707, with De subitaneis mortirbus..., G. M. Lancisi (1654-1720) had explained animal life as the balance among three functions and three fundamental organs: the heart, which coordinates blood circulation; the brain, which elaborates the vital spirit in the animal and sensitivity and infuses it to all the parts of the body through the nervous fluid ; the lungs which purify and invigorates the blood through breathing. Death is therefore caused, according to Lancisi, by the ceasing of one of these three functions as far as the postmortem outcomes have revealed, he had found the cause of sudden deaths in a cardiac hypertrophy, often associated to aneurisms or to the presence of "polyps" in the aorta. If aneurisms, polyps and morphologic alterations of the cardiac apparatus definitely compromise the cardiac-circulatory function as Lancisi had asserted in his work, determining immediate death of a single being, there are also other physio-pathologic conditions as syncope, fainting, apoplexies, that the medical literature of the eighteenth century explained as a simple suspension of the vital functions recoverable through specific stimulus techniques. M. Nurock has well underlined this in the XVIII century the terms reanimation and resuscitation do not mean, like today, the revitalization of a single being but only of specific functions, which in certain conditions are appeased/soothed. (Nurok M, 2003).

Reanimation therefore appears as a therapeutic act aimed at stimulating functions and the apparatus of an apparently not vital body that is not dead yet: the vital force is in fact mixed with the animal essence itself, and its lacking phenomenal reality does not necessarily assume its ceasing. In fact, a medium condition between life and death does exist, where the vital impulses are gradually even more appeased till they become silenced, and only later, in a period of time rarely definable, and eventually cease completely. These are the cases of 
apparent death. But how is it possible to distinguish between a condition which just appears to be death and certain death? Two are the basic epistemic references which come out: the individuation of the etiological causes which determine a "pathologic" condition of apparent death on one side, and the identification of the signs of legal death on the other. In relation to the latter, in fact, many authors of the eighteenth century refer directly to the evidence of the signs of decomposition of the body for the validation of the certification of death. As for the causes, a precise nosology picture is drawn from a specific pathologic outline and, in particular, from that accidentally induced, which though implying loss of willpower, knowledge and the movement of a single individual, and the lack of a clinical manifestation of vitality.

The basic principle is that the result of random casualties, like tumbling, asphyxia, or those caused by environmental factors or toxic fumes, ingestion of poisonous substances, strangulation or drowning, and some pathological forms which induce a state of apparent death, like syncope or apoplexies, are conditions of suspension of the vital functions and not the complete ceasing of them. Aid mainly consists in recovering those vital functions which have been "suspended" and can be recovered with specific medical-surgical interventions before they cease completely.

John Hunter (1728-1793) distinguished among three types of sudden death: the interruption of the vital action without any damages to the vital components; the result of an injury occurred to a vital part, like excessive bleeding, wounds or the cerebral and/or marrow compression; the immediate loss of vitality in all the parts of the body at the same time, as it happens in the case of fulmination, violent brain affections, or a blow to the stomach.

According to Hunter, the first signs of distinction between a real death condition and a state of suspension of the vital activities, is the presence or absence of spasms and contractions which occur when an individual is about to die, while the state of relaxation of the body can imply that the spastic stimulus preceding death has not aroused yet, and therefore that a drowned person could be possibly reanimated. Rigor mortis is the most evident sign of real death, because it is the consequence of the stimulus induced by the process of death. Viceversa, in many cases of sudden death, where such phenomena do not occur, blood does not coagulate and rigor mortis does not occur, the muscles stand still and soft. Until the animal preserves its "susceptibility of impression", even in the absence of vitality, can be reanimated, because it is reactive to external stimulus (Hunter J., 1837).

J. Janin too (1731-1811), Surgeon of the Royal Army and member of the Royal College of Surgery, faces the problem of the urgency of a criteria of legal death, which eliminates the risk of burying live people. The systems adopted so far, involving the incision or burning of the feet, or putting the flame of a candle under the nostrils, have in fact proved ineffective to check the effective presence or absence of sensitivity in an animal body. For this reason, it is necessary to find a system of coordinated procedures aimed at reanimating apparently dead people thus avoiding the risk for those who are still alive to be considered dead. According to Janin, sudden deaths are often states of apparent death, except for some specific pathologies, in particular those pertaining to the heart, while the presumed deaths by asphyxiation, indigestion, syncope, hypothermia, drowning, are often just a suspension of vitality which with proper intervention, can be completely restored. 
Charles Kite (1768-1811) is in contrast with the conventional methods of legal death by the arrest of the pulsations of the pulse and breathing, diagnosed with the flame of a candle or a tuft of wool or a mirror positioned in front of the mouth and nostrils. Using these methods, many individuals who were still alive, had been declared dead. For this reason it has been later considered the necrotic aspect of the body, like the fixed or flabby opaque state of the eyes, the formation of foam at the mouth and nostrils, the rigidity of the body, of the mouth and of the limbs, as a manifestation of decomposition and therefore as an indicative sign of real death. But it is necessary to distinguish between contraction caused by a spasm and the rigidity which arise by the lack of elasticity of the fibers subsequent to death.

Not even the fluidity of the blood can be an absolute sign itself, therefore death can be determined by a complex group of signs, which is now unanimously proved by the evidence of the beginning of the decomposition process. In apparent death there is the arrest of the circulation, breathing, and of the cerebral functions, though with a subsistence of irritability of the muscular fibers; in certain death (biological death) on the contrary, also the latter is lost. Therefore, according to Kite, the real difference between real death and apparent death consists in the presence or absence of the sensitivity, and the signs of death, which are considered indicative of the decease, are only consequences of the loss of the nervous and cerebral functions, but are not necessarily really certain.

The symptomatic outline of poisoning, drowning, and asphyxia, constitute in fact definite nosological realities, because, even though referring to specific pathologic categories, like apoplexy o paralysis, it is possible to define their causes, in the physio-pathologic processes, and in the therapeutic treatment.

It is this causal difference which creates the epistemological basics of first aid: together with the traditional concept of therapy as a system of healing which involves surgery (bloodletting, cauterization, amputations, extractions) and pharmacology intrinsic to the healing process, which include a proper regime to the specific pathologies, there is a therapeutic model of immediate treatment, where the physician, though remaining the necessary referee, can operate in a later moment, when the person has already been saved from the dangerous situation and has already received first aid, preparatory to the medical intervention itself.

In particular, it is the rescue of drowned people to constitute the basis for the theoretical studies, both on the importance of an immediate medical action and on the definition of the status of apparent death.

A rescue model for drowned people, had already been standardized in the XVII Century, based on the theoretical assumption that the arrest of the vital functions was due to the water flowing into vital organs. For this reason rescue techniques had been developed, aimed at expelling the water entered by hanging the drowned person upside down in order to clear the stomach and the chest, and stimulate those parts of the body by shaking them, slapping feet and palms of the hands, and placing the assisted individuals in a barrel opened on both sides, whirling it in many directions to shake them and stimulate in this way the vital organs and the animal vitality.

In contrast with the seventeenth and early eighteenth century authors, whom have dealt with drowned people, it becomes now relevant the timeliness of first aid in all cases of apparent death. Between the XVII and the XVIII Century, various authors, among which T. 
Bartholin, A. Borelli., F. Hoffmann, refer of cases where even after many hours of immersion, some drowned people have showed signs of vitality.

It is now under focus a univocal determination of the time by which the reanimation intervention can result effective and a uniform criteria of the practices of reanimation, so as to produce a corpus of regulations to follow in case of emergency, which could be taught and divulged even to non-medical people.

Through this method the majority of citizens are able to learn quick reanimation techniques, because the duration of transfer to the hospital or awaiting a physician or surgeon can be fatal. So, a specific medical literature on medical education is developed, in forms of "notices", "instructions", or didactic-popular manuals, with the purpose of informing the population on the risks of disease to which they can be exposed, teach them prevention and prophylaxis, systems of first aid and treatments to the victims of the most frequent casualties, in particular for drowned, asphyxiated and poisoned people and the dead born children, whose death is explained, according to the physio-pathologic theories of the time, with the alteration and/or ceasing of breathing induced by the lack of air and the subsequent interruption of the dynamics of blood circulation.

Through the study of these works, it is possible to analyze the effects which contemporary medical scientific studies have on the elaboration of a system of first aid.

\subsection{A.S. Tissot's Avis and first aid directions}

Recent French historiography has identified in the Avis au peuple sur sa santè... (Lausanne, 1761) by S. A. Tissot (1728-1797) the origin of first aid medicine (Larcan A. et Brullard Ph., 1979), even though such work is generally considered by the historians of medicine as an emblematic example of the process of popularization occurred to the medical culture in the seventeenth century. (Singy P., 2010; Riley J.C., 2001).

Undoubtedly, the wide spread of Tissot's work and other medical popular works, like $\mathrm{La}$ Médecine, la Chirurgie et la Pharmacie des Pauvres by P. Hecquet (1661-1737), written in 1740, the Domestic Medicine by W. Buchan (1729-1805) written in 1769, and the medical encyclopedias published in the second half of the eighteenth century, like the Dictionnaire de Santé in 1760 e il Dictionnaire de Médecine in 1772, contribute to the standardization of the treatment "protocols" for the necessity of simplifying therapeutic systems of the medicine of the time, and make them accessible to a public of non-experts.

In Tissot's Avis there are in fact some indications of first aid in specific cases, especially for occasional casualties, like asphyxia induced by environmental circumstances, drowning, asphyxiation caused by ingestion of foreign bodies which remain in the esophagus or obstruct the trachea, but also for blood apoplexy.

According to Tissot, an immediate treatment is necessary for all forms of fainting, defined as the loss of senses and motor faculties. He classifies fainting depending on its causes while the reanimation treatments vary in accordance with the etiology and physiopathology of the fainting state itself. In most cases, the author gives simple remedies, like the administration and inhalation of spirit liquor, specific food and drinks after the patient is reanimated.

But for certain cases of fainting, he also gives more complex first aid indications. In the most serious cases of fainting induced by blood excess, or due to constitution of the body or 
alcohol or food, it is necessary to immediately put hot water and vinegar on the forehead, temples and wrists; pass the vinegar under the nose; place ligatures to the thighs in order to avoid blood reflux.

If, in spite of this intervention, unconsciousness persists for more than a quarter of an hour, bloodletting from the arm and enema treatments were used; the patient is placed in a bed and every now and then some elderberry tea with vinegar and sugar is administered to him/her. Fainting caused by an excessive organic weakness, induced by hemorrhages, diseases, dysentery, urine flux or hunger, are treated by placing the patient in bed and rubbing the whole body with hot flannels; through the inhalation of spirit substances, like Hungary water, volatile salts or strongly aromatic herbs; some drops of Carmelite water or spirit or other liquor are poured into the mouth; flannel cloths tempered in hot wine or spirit are laid on the abdomen, and if unconsciousness persists the whole body is rubbed.

In case of more serious fainting due to nasal hemorrhages, ligatures of arms and thighs are placed, and to increase the effect, the legs are immersed in warm water up to the knees. Once the hemorrhage has been stopped, it is possible to remove the laces from the limbs, and every half an hour the patient is administered with seven or eight grains of nitre and water and vinegar; tampons made of linen soaked with white vitriol, or some Hoffmann's anodyne mineral liquor are inserted into the nostrils.

Innovative is the section relevant to the systems of first aid in case of asphyxiation due to the presence of foreign bodies in the throat, in the esophagus or in the trachea.

Tissot divides these bodies into those digestible, or rather food, and those indigestible, which can often be lethal, like rocks, pieces of glass or metal, sharpened objects, like nails or needles, which can penetrate the fleshy parts. The first can be pushed towards the stomach, with candlesticks, leeks, wooden sticks, or other tubular objects, possibly soft and very smooth in order not to damage the esophagus.

The indigestible objects instead, especially when sharp, must be extracted in order to avoid damages to the organs of the digestive apparatus. Obviously, the kind of treatment depends on the spot where the foreign body has stopped, on its nature and form: if it remains trapped at the entry of the esophagus, it is possible to extract it with the hands; if on the contrary it has gone deeper, it is possible to grab it with tweezers, and in case they are not available, it is possible to use two crossed wooden sticks. Whether it is not possible to extract it according to this regulation because it has gone too deep, it is possible to use a hook, or create it with a wire curved at one end, to be inserted down to where the body has been blocked and move it so as to hook it up when the instrument is extracted. Thin objects which through the use of the hooks could move away from the esophageal walls and go down into the stomach, must be recovered through the use of a ring, both solid or flexible, in order to hook them up. Tissot also explains how to build this instrument: it is possible to use a wire by bending it in the middle so as to form a circle with a diameter as wide as a finger, and drawing both ends up to use them like a handle and insert the ring into the esophagus in order to grab the object; but it is also possible to use wire rings, one into the other to make the catch even firmer, so that by pulling the ends, rings get tightened up and wrapped around the foreign object. Another system is that of inserting beneath the object a dried sponge that, when properly dampened, could swell up until it is able to un-stick it and lift the element to be extracted, or it is possible to fix a woolen or cotton tuft to a flexible 
handle or waxed thread, which is slipped below the object to be removed. A chapter of the work is dedicated to rescue drowned people. Tissot explains death by drowning as a consequence of asphyxiation induced by absence of air and presence of water into the respiratory tract, which mixing with the air still present in the lungs, forms a viscose foam that blocks the pulmonary functions; this way the circulatory motor is also arrested, and blood, unable to flow back to the head, remains into the cerebral vessels, where it is congested causing apoplexy. In order to save drowned people, it is therefore necessary to decongest the lungs and the brain and reactivate circulation. He lists in sequential order all of the operations to be carried out to reanimate a drowned person: 1) take off his/her wet clothes, rub him/her immediately with hot cloths and baths, even after having placed him/her in a warm bed; 2) insufflate hot air and tobacco fumes into the lungs, blowing into the patient's mouth through a stem or other tubular instruments aimed for that purpose; in this way the hot air introduced into the respiratory tract relaxes the pulmonary vessel and dissolves the foam, so as to reactivate blood circulation; 3 ) if there is a surgeon, bloodletting is practiced from the jugular in order to decongest the vessels of the head and neck; 4) tobacco fumes are introduced into the intestine, either with the proper fumigation apparatus or with a pipe, whose stem is inserted into the anus of the assisted person, and whose tobacco bowl is strongly poked, or upon which another pipe is positioned upside down to blow the fumes, or with stems and other tubular instruments; 5) some strong volatile liquors are passed under a patient's nose and powders of strongly aromatic herbs are blown into the nostrils; some drops of stimulating liquor are poured into the patient's mouth, and only after the assisted person shows signs of reanimation other substances can be administered; five or six spoonfuls of oxymel melted in hot water or thistle, sage or chamomile with honey, are recommended; the prescribed treatments are practiced even after the drowned person has been reanimated, till he/she recovers his/her full organic functionality.

Tissot's prescribed interventions show a deep knowledge of the debates of the time and on the physiopathology of drowning and above all on the reanimation systems to adopt in order to save drowned people. This results even clearer from the list of the reanimation operations which are still practiced, but which the author denounces to be useless and even damaging to the patients. He thus insists on avoiding to wrap drowned people with the skin of some sheep, cow or dog just slaughtered to infuse warmness; to roll them in a barrel and hang them up side down by their feet to expel the water. He formulates those remedies which will constitute the foundation of reanimation: the recovery of natural body temperature through baths and rubbing and the reactivation of the respiratory functions are essential interventions for reanimation. Even the paragraph dedicated to suffocation due to mephitic vapors or alcoholic liquors gives indications which are in accordance with the medicine of the time: in closed space, the sulphurous oil coming out from burning coal and the exhalations produced by the alcoholic fermentation saturate, making it so unsuitable for respiration to cause fainting, convulsions and apoplexy. In order to reanimate these asphyxiated persons it is necessary to transfer them immediately to the open air, making them inhale penetrating vapors, like the volatile spirit of sal ammoniac or English salt, and then vinegar vapors; the patient's legs are submerged into tepid water and massaged; in the meantime the patient is administered with some lemonade or water with vinegar and nitre and then receives enemas with acre substances. As soon as the asphyxiated person show signs of life, he/she receive antispasmodic drugs, like the Hoffmann's anodyne mineral liquor or opium. 
Many of Tissot's instructions are re-elaborated by W. Buchan (1729-1805) in Domestic Medicine, published for the first time in 1769, which widens the description of the techniques of first aid used to reanimate drowned people.

He illustrates various accidental casualties, describing both the symptoms and the physiopathologic process induced by them, and the rescue operations to perform. The systems of reanimation indicated by Buchan for the victims of hot or cold asphyxia, as well as for fainting, suffocation caused by toxic vapors and the extraction of foreign bodies from the esophagus, follow the instructions given by Tissot's Avis au peuple. More articulated is the description given on the reanimation of drowned persons, with implicit references to the instructions distributed by Drowning Persons Rescue Company and articles on this topic written by contemporary authors. Like Tissot, he underlines the importance of the time factor: when recuperated in a few minutes (quantified in about fifteen minutes), the reanimation interventions are easier and the result is surely positive; otherwise specific and more complex techniques must be adopted.

Drowned people must be immediately transferred to a proper place, making sure they do not suffer shaking, and once lying in a comfortable place with their head slightly lifted. As for all cases of apparent death, the main operation is the recovery of the natural body heat, basic element of all the vital functions; drowned persons must be therefore stripped of all their wet clothing, rubbed with coarse linen and wrapped in warm clothes or cloths. Hot bricks, wrapped in cloth, or hot water bottles are positioned under the feet and palms of the hands; if there is a fire or other source of heat, the patient is placed near it so as to receive proper warmth; otherwise it is sufficient that one or two people lay with the patients in order to infuse the warmness of their body. Nostrils are stimulated with exhalations of strong volatile spirit liquors, or tobacco or marjoram powder, and the chest and back are rubbed with a cloth soaked in a distilled beverage or spirit of hot wine prepared with volatile spirit of salt ammoniac.

At the same time, air is insufflated into the lungs, blowing exhaled breathe directly into the mouth of the drowned persons, making sure that both nostrils are held till the chest is filled and swelled; then the chest is compressed so as to expel the air introduced, repeating the operation until the patients recover their respiratory function. For artificial respiration, it is possible to use a reed that is inserted into one of the nostrils and closing the other and the mouth. In case the mouth of the patient is closed, it is possible to use a spoon handle to open it by levering the dental arch. Other organs are stimulated by introducing fifteen drops of volatile alkali into the mouth (that is spirit of volatile salt ammoniac) and practicing the insufflation of tobacco fumes into the intestines. If a fumigation apparatus is not available, two pipes may be used, with their bowls covered over, introducing one stem into the anus and blowing into the second pipe's stem to fire the bowl of the first one.

Alternatively, an enema of hot water, salt and vinegar can be practiced, or other stimulating spirit liquor. The drowned person is placed in hot water, or covered with hot ashes or salt or sand or cereals. The throat and the nose are stimulated with a feather, and some tobacco or marjoram powder should be applied to the patient's nostrils, the temples and the stomach area are massaged with brandy or wine spirit, and some drops of these liquors are poured into the mouth of the drowned person. When the patients have been reanimated, they are administered with oxymel melted in warm water, or a thistle, sage or chamomile infusion with honey; above all, it is necessary to keep the patients warm and stimulate them, giving 
them liquor every now and then. If the patients still cough and show a sense of oppression, bloodletting is practiced. Reanimation instructions for drowned people are true for those apparently dead by strangulation, because the suffocation induced requires the same type of stimulation and recovery of natural heat and of the respiratory function (Buchan W., 1774).

The rescue of asphyxiated and drowned persons described by Tissot and Buchan in their works fully represents the codification of rescue systems elaborated by physicians on behalf of the governmental institutions. In general, in the middle of the eighteenth century, there is a new health organization of local administrations on the rescue of the victims of casualties, especially for the drowned people, which distribute public advises containing instructions on how to save the drowned person and thus codifying a kind of reanimation protocol.

\subsection{Assistance to drowned people as a model of first aid}

In Paris, already in 1740 there is a planning for a first aid policy, with public advises which indicate the measures to adopt for reanimation.

The avis published in 1740 concerning assistance to drowned people and distributed all over the French provinces, gives many instructions concerning the traditional systems of rescuing people, like the practice of hanging the drowned person by the feet to expel the water ingested and penetrated into the body, which had already been advised against and to which barrel rolling is preferred, consisting in placing the drowned person in a barrel opened on both ends in order to be whirled in different directions, and the tickling of the throat and esophagus with the barb of a feather, rubbing till vomit is induced. It is necessary to strip the drowned person of all his/her wet clothes, wrap him/her in warm blankets, transfer him/her to a warm place and put him/her to bed; in order to restart the solid parts of the body apparatus, the drowned people are shaken repeatedly, spirit liquors are poured into their mouth, among which hot urine and a decoction of pepper and vinagra.

The fibers of the nasal ducts are stimulated with volatile spirits, like those liqueur vapors prescribed for apoplexy, the barb of a feather and insufflations of sneezing powders or tobacco. The insufflations of hot air in the mouth and intestines, through a cannula, a bellows or a syringe and the fumigations of tobacco into the intestines through the use of a broken pipe which blows into the body the amount of fumes which a single pipe would smoke, are largely diffused practices. In the most serious cases, it is recommended to call for a surgeon for bloodletting from the jugular in order to expel thickened blood in the brain, and eventually practice a tracheotomy.

The basic idea is that drowning determines apoplexy, which becomes the ultimate cause of death of a person. The lack of instructions concerning the ways by which interventions can be carried out together with the lack of a reward for those who saved drowned persons, induced the government to draw up a memoir which described all the recognized rescue systems aimed at the reanimation of the drowned persons; but the quantity and complexity of the indications given, involve running the risk that only the easiest and less efficient interventions were practiced. In 1755 Claude-Nicolas Le Cat (1700-1768), Surgeon at the Hôtel-Dieu de Rouen, is designated of examining the memoirs and affirms that air insufflations into the lungs is the operation necessary to reanimate drowned persons. He therefore describes a siphon to be introduced into the trachea, by lifting the epiglottis with a proper instrument; a small bellows is adapted to the siphon in order to blow air directly into 
the lungs. In the same year other surgeons at La Vile de l'Isle reduce to four the number of basic operations for reanimation: shaking, jugular bloodletting, air insufflations into the lungs and tobacco fumigations into the intestines. Other similar advices are given in that period. The consistent number of persons dead by drowning, induced the Dutch government to adopt safety measures, which eventually brought to the foundation of the Dutch Humane Society of Amsterdam in 1767. Well-defined instructions on the modalities and kinds of interventions to practice for the reanimation of drowned persons, are compiled and distributed thus forming the reference model of future lifesaving societies which would be instituted in other European countries. Rescue operations are officially delegated to city guards and the citizens are instructed through public advices, so as to give immediate assistance and delegate to physicians and surgeons only the specialized operations such as bloodletting and tracheotomy. In order to achieve the charitable aim to save drowned persons, the Dutch government distributed advices and pamphlets concerning the operations necessary to reanimate patients, offering six ducats or a gold medal as a reward to anybody, physician or not, who demonstrated with a certificate to have saved and cured a drowned person by following the proper procedures. Once the patient is recuperated from the water, it is necessary to immediately infuse warmness to the drowned person, even by using the savers' clothes or, when possible, hot woolen blankets; the patient is transferred to a house heated with a moderate fire or to a factory with working boilers, covered with blankets and infused with the heat of the savers' body, who should lie beside him/her; then the body is rubbed, particularly on the back along the spine, with flannel or cloths soaked with brandy, or scattering the patient with salt. At the same time tobacco fumes are insufflated into the intestines, and whenever specific instruments are lacking, a simple pipe, a common bellows or a knife's sheath cut at the tip can be used. A strong volatile salt, like spirit of salt ammoniac, must be applied to temples and nostrils; nostrils and throat must only be tickled, without introducing any liqueur, till the patient has recuperated the respiratory and swallowing faculties. In order to reactivate the lungs, a mouth-to-mouth resuscitation is practiced: the assistant blows into the mouth of the patient, blocking both nostrils with one hands and using the other to exercise pressure on the chest to breath the air out (Cogan T., 1773; Trubuhovich RV., 2006).

In France in 1771, Nicholas Pia, pharmacist and alderman of the Municipal Guards of Paris is in charge of distributing public advices concerning drowned persons life saving techniques, and organizing a police service for the town municipality. It thus constituted the life saving Society for drowned persons. In the instructions in 1771 it is indicated that once the drowned person has been taken out of the water, it is necessary to immediately alert the Guards who must be provided with a box containing the essential instruments for first aid. Pia in fact creates a box with all the instruments needed for the reanimation of the drowned persons to be distributed to the guards all around the cities together with the instructions concerning both the rescue operations to carry out and the way to use the instruments in the box for first aid drowning techniques. The box includes a tobacco container, a bellows to fire it, a flexible cannula. The cannula is inserted in the anus, and the other extremity is connected to the spout of the container of tobacco which is kept lighted through the bellows. In about three quarters of an hour, half an ounce of tobacco is burnt. The box also contains a small shirt and a woolen hat to dress and warm the drowned person, a small bottle of volatile spirit of salt ammoniac to soak some paper to be introduced into the nostrils of the drowned person; two pieces of flannel and a bottle of camphor grapevine water to soak 
them in order to rub the body with it; two boxes of emetics and an iron spoon. The fumigation instruments are essentially made of a cannula intertwined with a leather tube in order to prevent both the inconveniences of accidental obstructions and the risk of the exhalations coming from the digestive apparatus of the assisted person. Once taken out of the water, the drowned person should be transferred to the nearest Guards' building or other proper place where it is possible to carry out the essential reanimation operations and only later, should he/she be brought to the Hôtel-de-Dieu. A medical guards' regulation is constituted: it is establish that by twenty four hours the Guards' Sergeant is compelled to present a report to the city government on the methods and the outcomes of the saving procedures carried out; the government gives forty-eight lire for each rescue operation to be divided among those that have contributed in the rescue. Municipality Guards provide surveillance and drowning rescue interventions and refers directly to the Health Minister. A proper first-aid manual is codified, with the indications both of the operations and their sequence to be carried out. The drowned person must be undress of his/her clothes, covered with warm cloths and exposed to a source of heat; through the use of a cannula, warm air is insufflated into the mouth, accurately closing both nostrils; the tobacco fumes are inserted into the anus by means of a fumigation instrument which every guards' body should be provided with. When an immediate intervention of reanimation is necessary, due to the late arrival of the Guards, it is necessary to insufflate air through the use of proper tubular objects, like the sheath of a knife cut at the tip, or two common pipes placed with the bowls covered over so that one stem is inserted into the anus and the other is used to insufflate tobacco fumes into the intestines. In the meantime the patient's body must be repeatedly shaken, avoiding to let him/her lie too long on their back. The nostrils and throat are tickled with the barb of a feather and the nostrils are also stimulated with tobacco fumes, sneezing powders and volatile spirit of salt ammoniac. The body is massaged with cloths soaked in camphor distilled water, with the addition of spirit of salt ammoniac. Jugular bloodletting is also useful when practiced by an expert. As soon as the patient shows any sign of vitality and recovers his/her respiratory and swallowing functions, lukewarm water is administered; after that an emetic or camphor distilled water with salt ammoniac can be used. Those who take the drowned person out of the water and give first aid, receive twenty-four lire as a reward, for the same reasons by which eighteen of them are given to the Sergeant and the Guards whom have carried out all the necessary rescue operations.

A summary of such operations is distributed to all the city guards, and constitutes an integral part of Pia's box, with the indications concerning how to use the instruments necessary for the treatment of drowned persons (Pia P.N., 1773; Trépardoux F., 1997).

In England as well, methodic studies on drowning reanimation techniques are developed, above all those concerning pulmonary ventilation.

In 1773 the obstetrician Thomas Cogan (1736-1818) translated into English the Memoirs of the society instituted at Amsterdam in favour of persons drowned compiled from 1767 to 1771, which became the basic reference model for the foundation of a similar institution in England. In 1774, together with the pharmacist William Hawes (1736-1808), it is instituted the Humane Society of London for recovery of persons apparently drowned or dead.

In the same year, Alexander Johnson compiles a Short account of a Society of Amsterdam and Hamburg for the recovery of persons drowned, where it is reported how the Societies of 
Amsterdam, Hamburg and Paris dealt with such cases and describes many cases of resuscitation of apparently dead people resuscitated in many European cities, with the aim of founding a similar institution in England (Johnson A., 1773).

Already many publications and reports concerning the rescue experiences of apparently dead people, even written by English authors, have shown how the measures adopted to save drowned persons can be applied with the same success to many different cases where the vital force is only suspended, and it is therefore possible to reactivate all the functions and vital motions (Monthly Review or literary journal, 1776).

The instructions distributed by the Humane Society of London give the basic guidelines, in sequential order, on the treatments to perform in case of drowning resuscitation: first of all, it is recommended not to apply the old systems of barrel rolling, hanging the body upside down, violent shaking and stroking. Once the drowned person is taken out from the water, he/she must be brought to a warm and well-aired location, placed upon a bed with his/her head lifted; he/she must be covered with warm cloths and exposed to a source of heat, though not too close to the fire. In order to warm the body, hot water bottles are applied under the feet, to the knees and armpits, and hot cloths or bricks wrapped in linen and placed on the rest of the body, especially on the back. The best treatment would be that of bringing the patient to a factory where, with the purpose of processing some products, there are working boilers and large and well-aired rooms, and the environmental temperature is lukewarm and not extremely hot. It is necessary to immediately stimulate the vital factors reactivating the lungs and the intestines. Then air is blown directly into the mouth of the patient and tobacco fumes are injected into the anus, at the same time keeping the body warm through rubbing performed with hot cloths or salt, or flannel soaked in brandy or rum or other strong alcoholic or spirituous liqueurs; the sense of smell is stimulated by applying spirit of volatile salt or ammoniac in the nostrils, which must be smeared on the temples to stimulate the head nerves; both throat and nostrils are tickled with a feather to reactivate the functions of the digestive apparatus inducing vomit and sneezing. It is specified that these operations are also efficient for other cases of apparent death, like asphyxia, both caused by strangulation or excess of heat or coldness, fits of convulsions, apoplexy, suffocation caused by air polluted with toxic vapors, as it happens in the mines, shafts, caves or alcohol factories. Even though the reanimation techniques indicated by physicians were certainly more sophisticated, in general the rescue operations concerning apparent deaths, distributed through public advices, satisfy the need to use applicable systems which could be easily performed even by non-expert people, and non specific instruments, in order to guarantee the maximum performance of the first aid operations necessary to resuscitate drowned persons even in the absence of physicians and surgeons.

For tobacco fumes insufflations into the intestines, since the half of the XVII century specific instruments had already been perfected, among which the fumigation instrument created by Th. Bartholin, which constitutes the reference prototype of more complex apparatus developed at the end of the eighteenth century (Portal A., 1810).

But in the popular pamphlets and in the instructions drafted for the drowning lifesaving societies, the physician themselves give alternative indications on how to proceed with anal fumigations and artificial respiration in the absence of a specialized instrument, so that more and more people could operate reanimation. 
This is why it is possible to find indications on how to practice intestinal fumigations with two simple pipes, or on the kind of common tubular objects, and on how to use them, for the ventilation of the lungs.

\subsection{Drowning physiopathology to explain apparent death}

More complex are the disputes about drowning nosology and the reanimation techniques to perform. In particular, we can point out a substantial divergence on the cause of death by drowning, which some identify as the result of apoplexy, others as the arrest of the respiratory function, which determines blood congestion in the venous system, and those who indicate it in the disappearance of sensitivity.

In the first case the authors promote bloodletting, even from the jugular, in order to decongest the blood still present in the cerebral vases; while for the other cases blood evacuation can even be dangerous because it further deprives the body of its warmness and vital principle. In the same way, not everybody agrees on the usefulness and efficacy of electricity, promoted above all by those who find vitality and sensitiveness of the fibers already compromised by the cardio-respiratory arrest. The doctrinal differences on the physio-pathologic interpretation certainly have a relapse on the lifesaving procedures proposed by the authors. In particular, it is possible to identify two different currents concerning the system of insufflations of air into the lungs, and the methods to infuse heat. From a doctrinal point of view, the key element for the ventilation of the lungs is the different quality of the expired air, or the one insufflated directly or through the use of a cannula, or the atmospheric one, introduced with a bellow.

When the drowned persons lifesaving society of Amsterdam is founded, the mouth-tomouth resuscitation technique is advocated to reanimate respiratory functionality through the insufflations of air into the lungs. But already since the first years of the seventies in the eighteenth century, the Dutch society promotes the use of bellows, one for the injection and the other for the aspiration of air, only by practicing mouth-to-mouth resuscitation in extreme cases, that is in the absence of any instrument that could avoid direct contact with the patient. The fear of tainted vapors coming from the patient induce both the physicians and the lifesaving societies to promote the use of bellows and cannulas which became part of the instruments of lifesaving boxes distributed to the city guards.

In particular, the insufflations of air through a bellow is deemed necessary by those physicians who consider atmospheric air more suitable than burnt air to revitalize nerves and fibers. Especially after the diffusion of the studies concerning the discovery of oxygen ( or rather sulfur dioxide) made by Joseph Priestley (1733-1804), and in particular the publication of his "Observations on Respiration and the Use of the Blood" in 1776, many authors do not consider exhaled air suitable for resuscitation, because it is full of tainted phlogiston caused by the combustion occurring in the lungs during respiration. Atmospheric air, or that dephlogisticated through oxygen gas, is the vitalizing principle: by inserting the dephlogisticated air into the lungs of the drowned person, the elaboration of the blood still present in the veins is immediately induced, thus reactivating circulation and respiration. For this reason, many popular works containing the instructions to resuscitate drowned, asphyxiated persons, recommend the use of bellows or inhalation instruments to pump atmospheric air, while mouth-to-mouth resuscitation is only indicated in extreme cases when proper instruments are not available. 
J. Fothergill (1712-1780), member of the Royal College of Physicians, fellow of the Royal Society of London and of the Royal College of Physicians, and corresponding member of the Royal Medical society of Paris, in 1745 publishes his "Observations on the recovery of a man dead in appearance ...", where he describes the resuscitation system performed in 1744 by W. Tossach, surgeon of Alloa, in order to save a man, apparently dead by suffocation in a well. Once the body had been taken out of the water, W. Tossach immediately practiced mouth-to-mouth resuscitation, closing both nostrils with one hand and blowing intensely till the chest was full of air; as soon as the heart started beating again, he practiced bloodletting from an arm, stimulating at the same time the body of the patient by rubbing and lightly shaking the body. According to Fothergill, the mouth-to-mouth resuscitation technique performed by Tossach has the merit of being practicable by anyone, even in the absence of specific instruments or specialized personnel. From a theoretic point of view, according to Fothergill, when passing through the lungs, blood undergoes a relevant metamorphosis thanks to the vivifying action of pure air and to the dismissal of the toxic and phlogistic one; during drowning this process is interrupted and blood is immediately filled with phlogiston and noxious principle, thus damaging all the vital parts affected by it. The stagnation of phlogistic air provokes the obliteration of sensitivity, that is the vital factor par excellence together with natural heat, and according to Fothergill, insufflations of a small quantity of pure air (or rather that which is oxygenated) would be sufficient to modify the quality of the phlogistic air still present inside the pulmonary vases; but the complexity of such an operation makes the application difficult, and it is possible to reactivate the respiratory motion mechanically through the injection of atmospheric or expired air. The introduction of air into the lungs communicates the motion to the heart too, and therefore it should be well-balanced and controlled; for this purpose the adoption of bellows, as discussed by the Humane Society of London, can be a disadvantage because it makes it difficult for nonexperts to control the quantity of air introduced thus increasing the risks of damaging the lungs, while mouth-to-mouth resuscitation permits one to manage the quantity and modality of ventilation into the lungs (Fothergill J., 1783).

Upon W. Haews' invitation, in $1776 \mathrm{~J}$. Hunter published a research on the experimental studies conducted in 1755, where he gives an account on the outcome of the experiments concerning lung ventilation carried out on a dog. Once the dog's chest was opened, Hunter ascertained that the cardiac impulses and frequency varied according to the activation or the suspension of air insufflations, and that in the absence of it the heart swelled and blood coagulated, becoming thick and black in the left ventricle.

He concluded that resuscitation of drowned persons essentially depends on the reactivation of the respiratory function. For this purpose, he indicates the use of two bellows, one to inject and the other to inspire air, inserting the nozzles either in the mouth or in a nostril, without a connecting tube. According to him, the use of bellows permits one to immediately ventilate the quantity of air necessary to relax the lungs and expel it promptly, reproducing the natural respiratory mechanisms. He underlines the importance of how much time the body is under water to have an efficient reanimation, the faster the rescue operations are of drowned persons' from the water the easier it will be. When there is immediate intervention, it is sufficient to practice artificial respiration to reactivate the vital functions; if, on the contrary, the patient stays on in the water for a long time, a more complex protocol must be carried out, involving many different operations to be performed contemporarily. In these cases, in fact, it is appropriate to insufflate stimulants, like volatile alkali vapors 
(that is spirit of salt ammoniac), through the mouth or the nostrils in order to stimulate the sense of smell; to apply to the nostrils spirituous acid substances, whose exhalations stimulate the nervous and sensory motions. During air insufflations, it is necessary to press the larynges into the esophagus, both to avoid air penetration into the stomach and into the intestines, and to insert stimulants; in the meantime a warm bed is prepared on which to lie the patient, because only heat can restore the vital principle, but without exposing the drowned person's body to an excessive source of heat, because this could also be lethal. Body temperature must be, in fact, gradually restored, not to create spasms and shocks. For this purpose, volatile alkali can be used, or heating and stimulating balms can be used to soak the blankets to be wrapped around the body, and to be injected into the stomach and the intestines, in order to warm and reactivate internal organs. When all these operations are not efficient, Hunter proposes the use of electricity to stimulate the heart. He considers, in fact, apparent death a condition of permanency of the animal sensitivity, even in the presence of a suspension of the vital functions. The stimulus impressed by the electric shocks on the chest, can reactivate the cardiac fibers and recover their functionality. Disagreeing with the thesis of death by drowning as a result of apoplexy, he discourages bloodletting because bleeding would further deprive the patient of the heat and vital principle. For the same reason he condemns the use of emetics and laxatives, which would weaken even more the animal apparatus (Hunter J., 1837).

William Cullen (1710-1790) draws up a memoir on the resuscitation techniques, on behalf of Lord Cachart, President of the Board Of Police in Scotland and promoter of the drowned persons rescue organizations and the distribution of instructions and public advices on this matter in the Scottish cities.

Contrary to the traditional systems of barrel rolling, hanging people upside down and stroking, Cullen affirms that a light shaking of the body is sufficient to reanimate a person only when promptly taken out of the water, but it is contraindicated in the other cases. According to him life does not cease immediately after the interruption of the pulmonary and cardiac activity, because vitality is also given by the nerves and the fibers, or rather by sensitivity from which heart activity depends on.

An essential assumption to reanimate the persons apparently dead, is the recovery of heat, because it is the necessary element to the vitality of the fibers. It is therefore by acting on this vital principle that it is possible to recover pulmonary and cardiac functions and reactivate blood circulation. The first operation to be carried out is therefore body heating, by undressing the patient of his/her wet clothes, transferring him/her to a warm place where there is a burning fire or a working furnace. When it is possible to have hot water, it would be appropriate to immerge the patient into it, because it is the safest and fastest way to recover the body temperature. If the drowned person is thin, he/she can be warmed with the heat of another person's body, then it would be good to have the patient lying down in bed with one or two people. The drowned person must lie down, preferably on their side, keeping his/her head slightly raised. Disagreeing with rubbing, he recommends to apply spirit of salt ammoniac to wrists and ankles and cover the body with cereals or ashes or hot sand or common salt. In the meantime it is necessary to perform all the intervention required to reactivate the fibers of the organs, starting from the intestines which are the ones that mostly maintain the sensitivity. In order to stimulate the intestinal fibers, he proposes tobacco fumes insufflations. In the absence of a proper fumigation instrument or of two 
pipes useful for the operation, it is possible to inject hot water with a syringe. Contemporarily lungs ventilation is performed, following the method adopted by Alexander Monro, that is blowing air into the mouth or in the nostrils through a cannula. Against those who consider expired air unsuitable for the reactivation of the vital functions, because it is rich in phlogiston, Cullen believes that hot air exhaled from another animal is the most efficient way to reactivate pulmonary fibers; only when such an operation does not achieve the hoped result, insufflations of air is practiced with two bellows, as proposed by J. Hunter. In order to ease air passage through the trachea, the larynges are kept down so as to alternate air insufflations and pressures on the chest which reproduces the natural motion of the lungs. If it is not possible to introduce air in this way, a cannula is directly inserted into the trachea: the surgeon stands on the right of the patient and introduces the index finger of his left hand into the mouth up to the epiglottis and with his right hand he inserts the catheter below the epiglottis. The external extremity of the cannula is then joined to a syringe full of air. Tracheotomy is practiced only as an extreme measure. As opposed to Hunter, he considers jugular bloodletting as a useful operation to dissipate vein congestion, which he believes being a cause of death by drowning. In order to reanimate the other parts of the body, in the most sensitive areas stimulants are used, such as the lime spirit and salt ammoniac. He rather warns about the risks induced by the usual practice of introducing spirituous fluids into the mouth before the patient recovers the respiratory and swallowing functions, and recommends to inject hot wine directly into the stomach through a catheter inserted into the esophagus. Even though following some of the directions given by W. Cullen, the instructions published and distributed to all of the Guards' Houses by Lord Cathcart faithfully following the advices already provided by the drowned persons lifesaving societies of other countries. To recover the natural temperature of the body, for example, in addition to the application of sand or cereal or hot ashes, it is also recommended to use bricks or bottles of hot water to put on the extremities of the body and the rubbing with alcoholic liqueurs; above all the traditional mouth-to-mouth resuscitation is practiced by closing both the nostrils of the drowned person and exercising alternate pressure on the chest to make him/her exhale the air inside it (Cullen W., 1776).

Other authors, mostly French, editors of popular texts, rather tend to figure drowning to be among the other forms of asphyxia. The different forms of asphyxia are noticeably divided according to the cause which determines them: foul or toxic air, excess of heat or coldness, syncope, strangulation and drowning. It is especially the thickening of viscous humors in the bronchus and in the throat together with blood coagulation, induced by the cold water, to render the reanimation of drowned persons more complex than it could be for those asphyxiated.

According to J. Janin (1731-1799?), with the arrest of respiration and the suspension of blood circulation, the electric fluid is restrained and for this reason natural temperature also fails. Janin compares the nervous fluid to a lantern which enlightens till it can burn air, and when this one expires, the sensitivity of the parts fades away. Consequently, in order to resuscitate drowned persons it is essential to restore the natural temperature of the body necessary to stimulate the nervous fluid which starts again to irritate all the membranous and muscular fibers till they recover the systaltic motion and melt the congested fluids; thanks to the stimulating action of tobacco, the intestines recover their peristaltic motion. Insufflations of air into the lungs is then practiced by blowing directly into the mouth of the patient and closing both nostrils well. Once resuscitated, the patient is administered with some 
spoonfuls of distilled spirit. As well as his contemporary authors, he considers electricity one of the most efficient instruments to test the existence of the vital fluid which, together with air, are the primary elements of vital motions and animal functions. He also finds a strong analogy between apoplexy and strangulation, because in both cases, there is a complexion of the brain vessels, and it is possible to adopt the same systems of reanimation. In order to save asphyxiated person from mophetic or putrid exhalations, it is necessary above all to remove the patient out of the place where there is foul air, undress him/her and rub him/her with hot water and vinegar to infuse heat; it can also be useful to place under the nose cloths soaked in spirit of vinegar and to tickle the nostrils with a feather (Janin J., 1772).

In a letter published on the Mercure de France in August 1772, Jacquin affirms that, together with the four operations (shaking, bloodletting, insufflations of air into the lungs and fumigation of tobacco fumes into the intestines) indicated in the advices provided by the Prevôt des Merchands et Echevins (Provost of the Merchants and Echevins), it is appropriate to place the drowned person on a bed of hot ashes in order to stimulate with heat the recovery of blood circulation. According to his project, every station of the Guards' House in each city must have a folding bed, a barrel of ashes, an iron heater with its trivet and two stoves to treat the patient as soon as he/she is saved, immediately warming the ashes. All the other operations of resuscitation can be in fact carried out while the patient is lying on the bed under which burning stoves are placed to keep the ashes heated. Thence starts a real debate on whether to use ashes as an essential instrument of intervention for the resuscitation of drowned persons. It appears that the process to obtain and keep them warm is hard and expensive, that the directions provided by the lifesaving society of Amsterdam, on which all the others have been based, does not mention it, and that the same effects can be obtained through other systems of body heating. Besides, those who advocate body aspersion with the ashes are condemned by those who believe that the thin powders coming from it, together with the alkali salt contained in it, can be toxic to the patient, as well as mephitic can be the burning coals used to create and keep the ashes warm (Pia P. N., 1773).

Also Joseph Jacques de Gardane (XVIII cent.) includes drowned persons in the nosology category of asphyxia, or rather apparent death by apoplexy induced by the arrest of the circulatory motion which is due to inhibition of the respiratory function provoked by lack of air.

In the case of asphyxia caused by lack of air, the patient should be taken out of the place where he/she is lying, exposed to open air, placed on his/her side and with his/her head slightly raised, undressed of his/her clothes and rubbed with fresh water, refrigerating and stimulating substances such as vinegar, wine or other spirituous liqueur to stimulate blood circulation. Before administering him/her with any treatment, it is good to wait for the reactivation of the respiratory and swallowing functions.

In the case of asphyxia by mephitism, instead, (that is caused by pathogen exhalations due to decomposition of putrefied organic matter, alcoholic fermentation, coal fumes, or foul air in closed places), the patient must be immediately transferred to open air, undressed and rubbed with cold water and vinegar; insufflations of air into the lungs is practiced, some ice is placed in the armpits, under the feet and on the pit of the stomach; only after resuscitation he/she is exposed to a fire. In asphyxia by coldness, before exposing the patient to any source of heat, he/she is sprinkled with snow or freezing water, because a very violent passage from low to high temperatures could be fatal. 
In order to reanimate a person asphyxiated by strangulation, jugular phlebotomy is practiced together with blowing air directly into the mouth; once he/she has recovered, a fan or bellows are used to ventilate with the aim of helping him/her to breath. If the cause is the presence of a foreign body into the throat, it is necessary to push it down or extract it. The persons asphyxiated by drowning, must be transferred to a dry place, covered with cloths soaked either in simple distilled spirit or camphor spirit and exposed to a moderate fire to help recover the natural body temperature. Once the patient has been disposed on his/her side, air is insufflated into his/her lungs through a proper tube or with the stem of a pipe inserted into one of the nostrils while the other is closed, or in the mouth. The fastest way is that of mouth-to-mouth resuscitation to better stimulate the expansion of the bronchus. Then tobacco fumes are introduced into the intestines through an instrument composed of a small cannula. It must be inserted into the anus, whose extremity is successively joined to a flexible tube linked to a pipe which is used to blow air into it. In the absence of such an instrument, it is possible to provide the same treatment with two common pipes, with their stems connected; in the meantime the patient should always be shaken and resuscitated by tickling the nostrils and throat with the barb of a feather, or by insufflating tobacco fumes, stroking his/her feet and the palms of the hands with small sticks. As soon as the drowned person recovers his/her swallowing ability, he/she is administered with some drops of camphor distilled water, volatile salt ammoniac, or other spirituous liqueurs. Recommended are also hot baths and/or aspersion of the ashes, rubbing with salts along the crural arteries, application of bread cooked in distilled water below the mammas and on the pit of the stomach, enemas of decoction of tobacco and common salt, bloodletting(Scelta di opuscoli interessanti tradotti da varie lingue, 1775; Gardanne J. J., 1783).

He holds the thickening of black blood into the heart, discovered in the postmortem examination, responsible for the non-elaboration due to the lack of dephlogisticated atmospheric air. By inserting dephlogisticated air into the lungs of the drowned person, it is possible to induce immediately the elaboration of the blood still present in the vessels thus reactivating circulation and respiration. When water has been accumulated into the small vesicles of the lungs, it is necessary to expel it to insufflate atmospheric air. For such purpose, Gardane creates a special instrument, aiming at both aspiring the water still present in the respiratory tract and introducing in it about a hundred cubic inches of air, to expand them at the maximum level and infuse heat(Biblioteca della più recente letteratura edico-chirurgica 1794).

A key point in the codification of the rescue operations to asphyxiated persons is the work of Antoine Portal (1742-1832), who since 1772 had drawn up a series of reports on resuscitation of asphyxiated persons on behalf of the Science Academy of Paris. In his account in 1772 "Sur les effets des vapeurs méphitiques", he follows some of the directions provided by Tissot concerning the rescue of persons asphyxiated by mephitic vapors, though widening the topic in the light of the new medical doctrines on the resuscitation of the apparently dead people. The patient is to be exposed to fresh air and moistened with cold water to counterbalance heat excess and blood rarefaction. It is then necessary to decrease brain pressure through bloodletting, in particular from the jugular, which would permit the evacuation of foamy blood. The patient is administered with vinegar mixed with cold water and with the same mixture enemas are practiced. Portal instead considers the administration of spirituous liqueurs and emetics dangerous but still largely diffused, 
because the efforts produced by vomit push blood to the brain. Diverging from his contemporary authors, he denounces the uselessness and dangerousness of tobacco fumigations into the intestines because the organs undergo a violent dilatation which compromises their vital functions and above all because fumes comprise the diaphragm on the lungs, thus obstructing inspiration. Thence he recommends to stimulate the intestines with vinegar or other irritating enemas and to insufflate air into the respiratory tract to reactivate blood circulation and therefore restore its functions.

The insufflations of air into the lungs can be performed by inserting a tube into one of the nostrils closing both the other and the mouth or practicing a tracheotomy and inserting a curved tube. The large diffusion of his work both in France and abroad, definitely asserts lungs ventilation with the rhythmical cardiac massage as the resuscitation technique for those who present a cardio-respiratory arrest. In contrast with other authors, Portal recognizes in water penetration into the lungs the primary cause of death by drowning. The data observed induce him to give value to the etiologic interpretation supplied by A. Borelli: the foamy liqueur is produced by the water entering the lungs and it obstructs respiration so that blood, not being able to flow along the pulmonary vessels, accumulates in the pulmonary artery and the subject dies by suffocation. The interruption of the mechanics of blood circulation, blocked by the accumulation of water into the respiratory organs, causes the death of the persons drowned. Resuscitation procedures of the drowned persons faithfully follow what he proposed for the rescue of asphyxiated by mophectic vapors. First, the drowned person must be undressed, preferably using scissors or other instruments which would permit to remove the clothes off without shaking the patient; it is necessary to transfer him/her to a proper place, with a cot or cart, so that he/she lies down on his/her side in an improvised bed, with his/her head slightly raised to ease foam expulsion thus permitting the blood to penetrate the vessels and reach the brain and the thoracic organs. The physician must check whether on the body there are any injuries or contusions, because the level of seriousness of the lesions can indicate if the patient has already died or, however, he/she has suffered too serious injuries to be saved or if resuscitation operations can be really useful. The rubbing is practiced all over the body with a hot cloth to warm it and eliminate the mucous and glutinous substances which often entirely cover the drowned persons body and obstruct the dynamics of transpiration. In order to decrease the serum thickened in the respiratory tract, it is necessary to blow directly into the trachea and from here into the lungs. To do so, it is necessary to close the nostrils of the patient with one hand to prevent air recovery, while using the other to exercise pressure alternatively on the chest so that the respiration is restored, which is necessary to reactivate the blood circulation. He condemns tobacco fumes fumigations into the intestines which can excessively dilate the organs of the digestive apparatus till they are damaged, or push them towards the top till the diaphragm is compressed thus obstructing further respiration and make artificial respiration useless. As for those asphyxiated by toxic vapors, air insuffflation is practiced by blowing in a tube inserted into one of the nostrils or, through tracheotomy, directly into the trachea. In order to infuse heat, blankets are used and hot bricks wrapped in linen cloths are placed under the feet. Jugular bloodletting must be practiced only when the drowned person does not show any signs of life. In order to resuscitate an asphyxiated congealed person, he/she must be wrapped in a blanket, transferred to the closest house and put in a non-heated bed; to reestablish the natural body temperature without causing a shock, the patient must be immersed in room temperature water and every two or three minutes hot 
water must be poured into the bathtub so that in fifteen minutes a temperature of 20 degrees on the Reaumur thermometer should be reached. As soon as the pulse is felt, more and more hot water is to be added till twenty-five degrees are reached thus restoring the right temperature. In the meantime, compresses of cold water on the face are applied, the nostrils are tickled with the a feather, spirituous substances are passed under the nose and air is insufflated into the lungs through a cannula inserted into one of the nostrils. When the patient is not reanimated or presents congealed limbs, rubbing distilled spirit or camphor vulnerary water is practiced all over the body and he/she is wrapped in blankets and placed in a warm bed. Once reanimated, the asphyxiated person is nourished only with liquids in particular with infusions of vulnerary plants or elderflowers and some drops of volatile alkali (Portal, A. 1810).

To contrast the effects of asphyxia by heat excess, the patient is transferred to a moderately cooler place, so that the body gradually adapts to the temperature change. The intervention of reanimation involves bloodletting (preferably from the jugular even in this case), the application of leeches to the temples and, when the patient can swallow, the administration of cold water with some vinegar, also used for enemas, and a footbath in lukewarm water (Portal, A. 1776).

According to these authors, from a physio-pathological point of view, the differences between the rescue operations aimed at saving drowned persons and those focused on asphyxiated persons by toxic air and heat, depend essentially on their different alteration of blood mass: in the case of drowning, blood thickens and coagulates; in the case of heat strokes and asphyxia caused by foul air, coal smoke and exhalation of alcoholics or putrefied matter, blood becomes foamy and rarefied. In both cases apoplexy is generated and for this reason each person is treated with jugular bloodletting and some treatments and stimulants are used to revitalize the parts of the body; but while the asphyxiated persons are to be exposed to fresh air and moistened with cold water, drowned persons essentially need to recover their natural temperature and reactivate their respiratory function in order to stimulate the recovery of blood circulation and therefore the heart.

\section{Conclusions}

The rescue methods defined in the 1770s, when drowned persons lifesaving societies were developing, are more or less the same till the beginning of the nineteenth century. In accordance with the medical techniques and Brown's doctrine, the reanimation procedures essentially consist in a stimulation of the vital factors, heat and sensitiveness, and internal motions, which should restore those functions compromised by a violent external event, as it happens in casualties.

The concept of apparent death, defined as an organic state of suspension of the vital functions which does not imply the end of life itself, not only makes it necessary to discover new strategies to certify death, but also interventions aimed at resuscitating those individuals whom, in the absence of a pathological status or injuries to the organs, have preserved the vital force. This is why drowned persons represent an important paradigm, because their condition is induced at least by two different factors of interruption of the natural vital impulses, the coldness of water and lack of air, without even considering the trauma caused by falling in the water. For this reason, reanimation procedures imply both 
body heating, to restore its natural temperature, and the stimulation of different apparatuses, the respiratory one in particular. The insufflations of air, beyond the doctrinal and technical divergences among various authors, is universally recognized as a good instrument to stimulate pulmonary process and, through the movement inferred to the lungs, the blood still present in the cardiac vessels. The methods used to save drowned persons thus represent the expression of the most complex practical system elaborated to rescue dying people in the seventeenth century and this is why it can be considered as the epistemic model of emergency medicine. This is the presupposition for the creation of effective therapeutic protocols to take care of more specific pathological categories, including resuscitation techniques. In particular, the artificial respiration, obtained by the insufflation of the air in the lungs and the alternating pressure on the chest, forms the basis of the medical resuscitation until the present day. The modern resuscitation developed in the late 50's of the last century, when Peter Safar (1924 - 2003), a specialist in anesthesiology, codified the "mouth to mouth" breathing to revive the patients unable to breathe autonomously. In the early '60, the engineer William Kouwenhoven (1886 - 1975) codified the rules for the external cardiac massage (MCE). Safar continued his studies on this specific medical field, writing the $\mathrm{ABC}$ of resuscitation, i.e. A for Airway, B for Breathing and $\mathrm{C}$ for Circulation. In the same times, the Laerdal, the Norwegian industry of medical instruments, produced the "Resusci Anne", the first human mannequin for the teaching of the artificial respiration as the first medical step of resuscitation. In the early '70s of the Nineteenth century, the American Heart Association (AHA) codified the guidelines for the teaching of homogenous CPR techniques, still used and taught to the medical practitioners and to the health professionals

\section{References}

Biblioteca della più recente letteratura medico-chirurgica, Tomo III, parte I (1794), pp. 98115.

Buchan, W. (1774). Domestic Medicine or the family physician. Philadelphia, USA

Cogan, T. (1773). Memoirs of the society instituted at Amsterdam in favour of drowned persons. London, England

Cullen, W. (1776). A letter to Lord Cathcart concerning the recovery of persons drowned and seemingly dead. London, England

Fothergill, J. (1783). The works of John Fothergill, London, England

Gardanne, J. J. de (1783). Catéchisme sur les morts apparentes, dites asphyxies . Dijon, France

Hunter, J. (1837), The works of John Hunter (ed. by J. F. Palmer), London, Vol. IV, pp. 165175.

Janin, J. (1772). Réflexions sur le triste sort des personnes qui sous une apparence de mort, ont été enterrées vivantes... Paris, France

Johnson, A. (1773). An account of some Societies at Amsterdam and Hamburg... London, England

Kite, C. (1788), An essay on the recovery of the apparently dead, London, England

Larcan, A.; Brullard, Ph. (1979). Remarques concernant la prévention, la notion d'urgence et l'organisation des secours au XVIII siècle. Histoire des Sciences medicale, Vol. 13, No. 3, pp. 271-278, ISSN 0440-8888

Monthly Review or literary journal 1776; june 1773-january 1774. 
Nurok, M. (2003). Elements of the medical emergency's epistemological alignment: 18-20th perspectives. Social Studies of Sciences, Vol. 33, No.4, pp. 563-579, ISSN, 0306-3127

Pia, P. N. (1773). Détail des succès de l'établissement que la vile de Paris a fait en faveur des personnes noyèes..., Paris, France

Portal, A. (1776). Rapporto fatto per ordine dell'Accademia delle Scienze sopra gli effetti dei vapori mofettici, Parigi, France.

Portal, A. (1810). Istruzioni sopra la cura degli annegati, degl' Asfissiaci, delle persone morsicate... Paris, France.

Dalla stamperia di Vincent, ParigiRiley, J. C. (2001), Rising Life Expectancy: A Global History, ISBN 0521802458, Cambridge, England,

Scelta di opuscoli interessanti tradotti da varie lingue (1775). Milano, Lombardia, vol. VII.

Singy, P. (2010). The Popularization of Medicine in the Eighteenth Century: Writing, Reading, and Rewriting Samuel Auguste Tissot's Avis au peuple sur sa santéby. Journal of Modern History, Vol.82, pp.769-800, ISSN 00222801.

Tissot, S.A. (1769). Avis au peuple sur sa santè. Lyon, France

Trépardoux, F. (1997). Philippe-Nicolas Pia (1721-1799), échevin de Paris, pionnier du secourisme en faveur des noyés (II partie). Revue d'Histoire de la Pharmacie, Vol.85, No.316, pp. 375-384, ISSN 0035-2349.

Trubuhovich, RV. (2006). History of mouth-to-mouth rescue breathing. Part 2: the 18th century. Critical Care and Resuscitation, 2006, Vol. 8. No.2, pp. 157-171, ISSN 14412772 


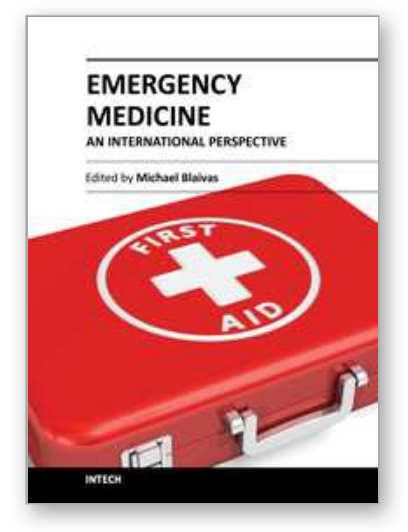

\author{
Emergency Medicine - An International Perspective \\ Edited by Dr. Michael Blaivas
}

ISBN 978-953-51-0333-2

Hard cover, 220 pages

Publisher InTech

Published online 16, March, 2012

Published in print edition March, 2012

Emergency Medicine is an expanding field that has spread beyond the shores of North America and has taken on different characteristics around the world. Although many of the struggles of emergency practitioners are similar, the field and its principles have adapted to local needs and resources. This book seeks to educate readers not only on emergency medicine theory, science and practice, but also reflects that multinational nature of emergency medicine, allowing readers to learn from experiences of others. This diverse group of authors presents a true international view of emergency medicine practice and science that will be educational for any reader.

\title{
How to reference
}

In order to correctly reference this scholarly work, feel free to copy and paste the following:

Silvia Marinozzi, Giuliano Bertazzoni and Valentina Gazzaniga (2012). Medical Instructions of the XVIII Century to Resuscitate the Apparently Dead: Rescuing the Drowned to Define the Origins of the Emergency Medicine, Emergency Medicine - An International Perspective, Dr. Michael Blaivas (Ed.), ISBN: 978-953-51-0333-2, InTech, Available from: http://www.intechopen.com/books/emergency-medicine-an-internationalperspective/medical-instructions-of-the-xviii-century-to-resuscitate-the-apparently-dead-rescuing-the-drownedto

\section{INTECH}

open science | open minds

\author{
InTech Europe \\ University Campus STeP Ri \\ Slavka Krautzeka 83/A \\ 51000 Rijeka, Croatia \\ Phone: +385 (51) 770447 \\ Fax: +385 (51) 686166 \\ www.intechopen.com
}

\author{
InTech China \\ Unit 405, Office Block, Hotel Equatorial Shanghai \\ No.65, Yan An Road (West), Shanghai, 200040, China \\ 中国上海市延安西路65号上海国际贵都大饭店办公楼 405 单元 \\ Phone: +86-21-62489820 \\ Fax: +86-21-62489821
}


(C) 2012 The Author(s). Licensee IntechOpen. This is an open access article distributed under the terms of the Creative Commons Attribution 3.0 License, which permits unrestricted use, distribution, and reproduction in any medium, provided the original work is properly cited. 